

\title{
HUBUNGAN ANTARA KEKUATAN OTOT LENGAN, PANJANG LENGAN DAN KELENTUKAN OTOT PUNGGUNG DENGAN KEMAMPUANLEMPAR TURBO PADA SISWA PUTRA KELAS IV DAN V SD N 01 GEDONGAN KECAMATAN BAKI, KABUPATEN SUKOHARJO
}

\author{
Ronny Suryo Narbito \\ Ronny.narbito@lecture.utp.ac.id \\ Universitas Tunas Pembangunan Surakarta
}

\begin{abstract}
ABSTRAK
Tujuan dari penelitian ini adalah untuk mengetahui: (1) Hubungan antara kekuatan otot lengan terhadap kemampuan lempar turbo pada siswa Putra Kelas IV Dan VSD N 01 Gedongan Kecamatan Baki, Kabupaten Sukoharjo 2020. (2) Hubungan antara panjang lengan terhadap kemampuan lempar turbo pada siswa Putra Kelas IV Dan VSD N 01 Gedongan Kecamatan Baki, Kabupaten Sukoharjo 2020. (3) Hubungan antara kelentukan otot punggung terhadap kemampuan lempar turbo pada siswa Putra Kelas IV Dan V SD N 01 Gedongan Kecamatan Baki, Kabupaten Sukoharjo 2020. (4) Hubungan antara kekuatan otot lengan, kecepatan lari dan kelentukan otot punggung terhadap kemampuan lempar turbo pada siswa Putra Kelas IV Dan V SD N 01 Gedongan Kecamatan Baki, Kabupaten Sukoharjo 2020.

Teknik pengumpulan data dalam penelitian ini adalah menggunakan teknik tes dan pengukuran. Adapun jenis tes yang digunakan adalah: (1) Pengumpulan data kekuatan otot lengan menggunakan Tespush-Up dari (Ismaryati 2006:123). (2) Untuk data panjang lengan menggunakan tes mengukur panjang rentang dari M. Furqon (1999: 21). (3) Pengumpulan data kelentukan dengan tes Sit and Reachdar ilsmaryati, (2006:101-102). (4) Tes kemampuan lempar turbo diukur dengan menggunakan tes lempar turbo dari IAAF Kid's Atletics (Suyono, 2002:19).

Berdasarkan analisis data dan pengujian hipotesis yang telah dilakukan, maka simpulan yang dapat diperoleh adalah: (1) Ada hubungan yang signifikan antara Kekuatan Otot Lengan dengan Kemampuan Lempar Turbo , $r_{\text {hitung }}=0,417$ $>r_{\text {tabel }} 5 \%=0,361$. (2) Ada hubungan yang signifikan antara Panjang Lengan dengan Kemampuan Lempar Turbo, $r_{\text {hitung }}=0,456>r_{\text {tabel }} \%=0,361$. (3) Ada hubungan yang signifikan antara Kelentukan Otot punggung dengan Kemampuan Lempar Turbo , $r_{\text {hitung }}=0,386>r_{\text {tabel }} \%=0,361$. (4) Ada hubungan yang signifikan antara Kekuatan Otot Lengan, Panjang Lengan dan Kelentukan Otot punggung dengan Kemampuan Lempar Turbo, $R_{y(123)}^{2}$ sebesar 0,457 $>r_{\text {tabel5 \% pada taraf }}$ signifikansi $5 \%$ sebesar 0.361 dan $\mathrm{F}_{0}$ sebesar $7.3101>\mathrm{f}_{\text {tabel }}$ pada taraf signifikansi $5 \%$ sebesar 2,89 .
\end{abstract}

Kata Kunci: Kekuatan Otot Lengan, Panjang Lengan Dan Kelentukan Otot Punggung, Kemampuan lempar Turbo 


\section{HUBUNGAN ANTARA KEKUATAN OTOT LENGAN, PANJANG LENGAN DAN KELENTUKAN OTOT PUNGGUNG DENGAN KEMAMPUANLEMPAR TURBO PADA SISWA PUTRA KELAS IV DAN V SD N 01 GEDONGAN KECAMATAN BAKI, KABUPATEN SUKOHARJO (Ronny Suryo Narbito)}

\section{PENDAHULUAN}

Atletik Kids adalah jenis olahraga dari cabang atletik yang diperuntukkan khusus untuk sekolah dasar.Jenis cabang olahraga ini diperkenalkan pertama kali oleh IAAF (International Association of Athletics Federation).Kemudian disebarkan di sekolah-sekolah melalui berbagai pendidikan dan pelatihan oleh Pusat Pembinaan Atletik Pelajar (PPAP). Sebagai ibu dari semua cabang olahraga, sudah pada tempatnya atletik meniadi cabang olahraga wajib bagi pelajar sekolah dasar.Departemen Pendidikan Nasional pun menyetujui anjuran PB.PASI agar cabang atletik yang dimainkan adalah Kids' Athletics yaitu program pembinaan atletik bagi atlet usia pelajar sekolah dasar sesuai dengan kebijakan IAAF (International Association of Athletics Federation). Dengan dijadikannya Kids' Athletics sebagai cabang olahraga resmi.PB.PASI telah berhasil mensosialisasikan atletik di tingkat sekolah dasar di Indonesia.Melalui usaha ini.diharapkan atletik semakin digemari oleh anak-anak dan bibit-bibit baru semakin banyak ditemukan.

Dalam perkembangannya olahraga ini termasuk berjalan sangat pesat, terbukti dengan banyaknya usaha pemerintah dalam penyelenggaran kejuaraan atletik kids ditingkat paling bawah yaitu pada masyarakat umum sampai dunia pendidikan formal. Olahraga ini bahkan sudah meniadi trend pada tingkat pendidikan dasar. Di SD N 01 Gedongan Kecamatan Baki, Kabupaten Sukoharjo, Atletik Kids juga diajarkan dan banyak digemari para siswanya, khususnya nomor lempar turbo. Olahraga ini banyak digemari oleh para siswa, namun masih hanya sebatas senang atau suka dengan olahraga ini.Selama beberapa waktu ini belum terlihat hasil yang maksimal dari hasil pelaksanaan event-event perlombaan ini.Semua ini mungkin tidak terlepas dari beberapa unsur yang melatar belakanginya sehingga hasil yang diraih belum maksimal.

Upaya untuk mencapai prestasi dalam olahraga, merupakan hal yang berpengaruh terhadap prestasi olahraga.Pengembangan metodologi pelatihan merupakan salah satu hal penting yang ikut menentukan terhadap pencapaian 


\section{HUBUNGAN ANTARA KEKUATAN OTOT LENGAN, PANJANG LENGAN DAN KELENTUKAN OTOT PUNGGUNG DENGAN KEMAMPUANLEMPAR TURBO PADA SISWA PUTRA KELAS IV DAN V SD N 01 GEDONGAN KECAMATAN BAKI, KABUPATEN SUKOHARJO (Ronny Suryo Narbito)}

prestasi olahraga.Peranan ilmu pengetahuan dan teknologi sangat penting bagi pengembangan teori dan metodologi latihan olahraga.

Latihan adalah suatu proses mempersiapkan organisme secara sistematis untuk mencapai prestasi maksimal dengan cara diberikan latihan beban fisik dan mental yang teratur, terarah, meningkat, dan berulang-ulang waktunya. Latihan yang benar itu harus mempunyai tujuan dan sasaran yang ingin dicapai dengan menggunakan metode-metode serta pola dan menggunakan prinsip-prinsip latihan yang mempunyai pengaruh terhadap hasil olahraga lempar turbo.

Kondisi fisik menurut M. Sajoto (1995: 8) adalah, "Satu kesatuan utuh dari komponen-komponen yang tidak dapat dipisahkan begitu saja, baik peningkatan maupun pemeliharaannya. "Untuk mewujudkan hal tersebut, diperlukan kemampuan khusus yang sesuai dengan kebutuhan dalam penguasaan teknik lempar turbo yang baik. Kekuatan atau daya ledak merupakan kemampuan memadukan antara kekuatan otot dengan kecepatan gerak.Dalam teknik lempar turbo banyak kekuatanotot-otot yang diperlukan agar dapat menghasilkan lemparan yang baik dalam arti jauh, diantaranya tersebut adalah otot-otot lengan, dan otot tungkai disamping itu diperlukan juga keseimbangan. Keseimbangan merupakan kemampuan mempertahankan suatu posisi tanpa kehilangan kontrol keseimbangan.Untuk mewujudkan hal tersebut, diperlukan Kemampuan dan keterampilan khusus yang sesuai dengan kebutuhan yang diperlukan dalam melakukan lemparan.

Panjang lengan dalam lempar turbo sangat dibutuhkan untuk dapat mendukung pencapaian keterampilan dan kekuatan melakukan lemparan turbo, karena dengan memiliki lengan yang panjang terdapat keuntungan secara mekanis terhadap panjangnya rentang lengan sebelum melakukan lemparan. 


\section{HUBUNGAN ANTARA KEKUATAN OTOT LENGAN, PANJANG LENGAN DAN \\ KELENTUKAN OTOT PUNGGUNG DENGAN KEMAMPUANLEMPAR TURBO PADA SISWA PUTRA KELAS IV DAN V SD N 01 GEDONGAN KECAMATAN BAKI, KABUPATEN SUKOHARJO (Ronny Suryo Narbito)}

\section{TINJAUAN PUSTAKA}

\section{a. Pengertian Atletik}

Atletik adalah cabang olahraga vans memerlukan kekuatan, kelincahan, daya tahan, dan kecepatan. Atletik terdiri atas nomor-nomor lari, jalan, lompat, dan lempar.Atletik adalah cabang olahraga yang paling tua.Atletik sudah dikenal manusia sejak zaman dahulu.Atletik banyak diperlombakan dalam pertandingan olahraga.

Atletik adalah, aktivitas jasmani atau latihan jasmani yang berisikan gerak alamiah atau wajar seperti jalan, lari, lompat, dan lempar. Atletik dilakukan di semua negara, karena nilai edukatif yang terdapat di dalamnya juga memegang peranan penting dalam pengembangan kondisi fisik, sehingga dapat menjadi dasar pokok untuk pengembangan atau peningkatan prestasi yang optimal bagi cabang olahraga lain dan bahkan diperhitungkan sebagai ukuran kemaiuan suatu negara, khususnya dalam prestasi olahraga. Atletik adalah gabungan dari beberapa jenis olahraga yang secara garis besar dapat dikelompokkan menjadi lari, lempar, dan lompat.Kata ini berasal dari bahasa Yunani "athlon" yang berarti "kontes".Atletik merupakan cabang olahraga yang diperlombakan pada olimpiade pertama pada 776 SM. Induk organisasi untuk olahraga atletik di Indonesia adalah PASI (Persatuan Atletik Seluruh Indonesia).

Atletik kids merupakan jenis olahraga dari cabang atletik yang diperuntukkan khusus untuk sekolah dasar. Jenis cabang olahraga ini diperkenalkan pertama kali oleh IAAF (International Association of Athletics Federation).Kemudian disebarkan di sekolah-sekolah melalui berbagai pendidikan dan pelatihan oleh Pusat Pembinaan Atletik Pelajar (PPAP).

Sebagai ibu dari semua cabang olahraga, sudah pada tempatnya atletik meniadi cabang olahraga wajib bagi pelajar sekolah dasar. Departemen Pendidikan Nasional pun menyetujui anjuran PB.PASI agar cabang atletik yang dimainkan adalah yaitu program pembinaan atletik bagi 
atlet usia pelajar sekolah dasar sesuai dengan kebijakan IAAF (International Association of Athletics Federation). Berdasarkan peraturan Pe ${ }^{r}$ satuan Atletik Seluruh Indonesia (PASI).nomor-nomor lomba Atletik Kids terdiri dari:

1) Kanga's escape (sprint dan gawang)

2) Frog Jump (loneat katak )

3) Turbo throwing (lempar turbo )

4) Formula 1 ( laririntangan, slalom )

\section{b. Lempar Turbo}

Lempar turbo adalah salah satu kegiatan nomor lempar pada kids athletic, yaitu kegiatan melempar dengan satu tangan untuk mencapai jarak tertentu (Lumintuarso, 2008:40). Untuk memperoleh jauhnya lemparan diperlukan kekuatan dan kecepatan gerak serta sudut pada saat lembing meninggalkan tangan. Turbo atau rudal adalah lembing yang terbuat dari peralon 1 dim dengan ujung dari kayu jati dan ekor imprabot, Panjang turbo adalah $40 \mathrm{~cm}$ dengan massa yang cukup ringan yaitu 350-400 gram dengan panjang $75 \mathrm{~cm}$ bagi anak sekolah dasar.

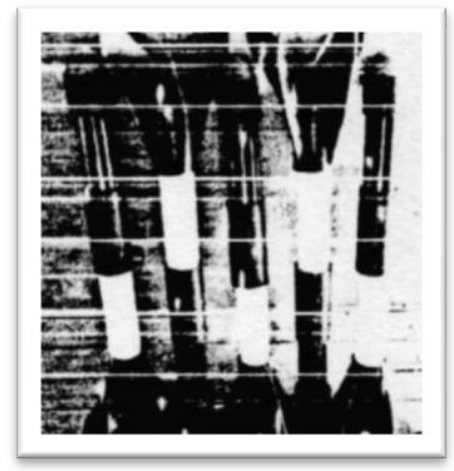

Gambar 1.Lembing Anak (Turbo)

( Nugroho_blogspot. com. diakses 3 November 2014 )

Prosedur lempar turbo diawali dengan awalan 5 meter, kemudian anak melempar turbo tersebut ke daerah lemparan yang dibatasi garis lempar, sebagaimana lempar lembing dewasa, faktor keamanan dalam kegiatan lempar turbo juga penting untuk diperhatikan, sehingga keamanan 
seperti kapan harus melempar turbo dan kapan mengambil turbo kembali harus dipatuhi oleh seluruh siswa.

\section{c. Teknik Dasar Lempar Turbo}

Ada beberapa teknik dalam pelaksanaan lempar turbo, teknik dasar yang diajarkan dapat dirinci meniadi tahapan-tahapan antara lain: (1) lari awalan, (2) lima langkah berirama untuk penarikan turbo. (3) lari lima langkah, (4) melepaskan lemparan turbo. (5) pemulihan. Pada saat gerakan tahapan awalan, pelempar turbo mempercepat gerakan atau akselerasi.Dalam tahapan gerak lima langkah berirama, gerakan dipereepat lebih lanjut dan pelempar mempersiapkan tahapan pelepasan turbo. Dalam tahapan pelepasan turbo, dihasilkan kecepatan tambahan dan ditransfer kepada turbo sebelum dilepaskan.Dalam tahap pemulihan, pelempar menahan dan menghindari berbuat kesalahan.

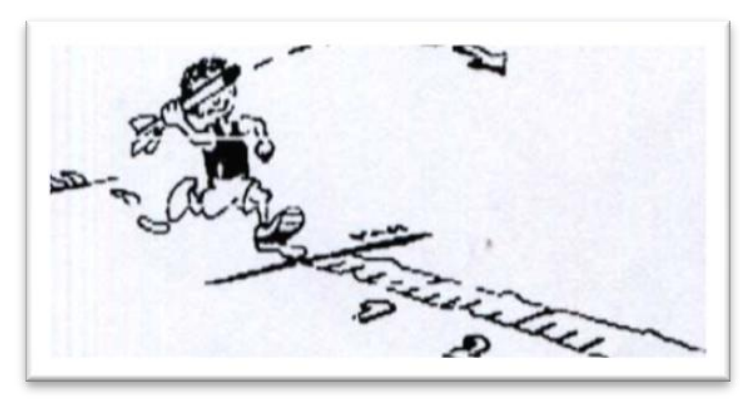

Gambar 2.Pelaksanaan Lempar Turbo (IAAF Kid's Alletics, 2002: 19)

Pelaksanaan lempar turbo diawali dengan awalan 5 meter. Setelah melakukan awalan pendek peserta melempar turbo ke area lemparan dengan dibatasi garis lempar.Setiap peserta melakukan dua lemparan.Karena keamanan cukup rawan dalam lempar turbo maka hanya guru yang boleh berada di area pendaratan lemparan.Sangat terlarang melempar balik turbo kearah batas garis lempar.Jumlah jarak terbaik dari dua lemparan masing-masing anggota tim merupakan hasil prestasi tim. Peralatan yang diperlukan diantaranya, lembing anak (Lembing Turbo).Garis 
ukur yang telah dikalibrasi dengan meteran, kartu lomba.Gawang dan Slalom.

\section{d. Otot Lengan}

Garis besar fisiologis otot dalam hal ini adalah hal-hal yang berkaitan dengan struktur otot, fisiologis otot, fungsi otot.Komponenkomponen penting dalam otot adalah actin dan myosin.Bila kedua komponen tersebut terpacu, maka filamen actin tertarik ke arah filamen myosin oleh cross bridge yang memiliki kedua filamen tersebut.Otot di dalam tubuh dapat dibedakan menjadi dua macam, hal ini sesuai dengan yang terdapat 2 macam otot ; (1). Otot seran lintang.(2). Otot Polos. Otot seran lintang atau disebut juga otot sadar, karena dalam bekerja atas kemauan kita, misalnya dalam mengangkat suatu benda, sedangkan otot polos dalam bekerjanya tanpa kehendak kita, misalnya dalam dinding usus.

Yang dimaksud dengan lengan adalah seluruh anggota gerak atas.Menurut Ahmad Sofian (1980: 49) :"Lengan dibagi dalam lengan atas, lengan bawah dan tangan. "Otot-otot lengan dengan fungsinya sebagai penggerak, dalam hal ini gerakan teknik mengayun lengan dalam melakukan smash, maka otot-otot lengan tersebut harus memiliki kekuatanyang baik.Kekuatanotot-otot lengan yang baik akan membantu dalam melakukan gerakan yang efektif dan efisien.

Lengan sebagai tulang anggota gerak atas mempunyai peran penting.Namun demikian untuk dapat melakukan gerakan tersebut secara sistematis merupakan hasil dari gerakan yang dilakukan oleh adanya system penggerak yang meliputi; otot, tulang dan persendian.

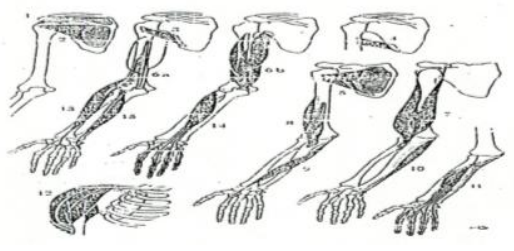

Gambar 3.Otot-otot pada Lengan

(Ahmad Sofian, 1980:310) 


\section{e. Kelentukan Otot Punggung}

Kelentukan atau fleksibilitas biasanya berkaitan dengan ruang gerak sendi-sendi tubuh, sehingga seseorang dikatakan lentuk atau tidak ditentukan oleh luas sempitnya ruang gerak sendi-sendi dari orang tersebut.Menurut Harsono (1993: 9) mengemukakan bahwa, "Jadi orang yang mempunyai kelentukan adalah orang yang mempu untuk menggerakan anggota-anggota atau bagian-bagian tubuh melalui ruang geraknya".

Andi Suhendro (2002: 447) mengemukakan bahwa, "Kelentukan (fleksibilitas) adalah kemampuan suatu gerak secara maksimal tanpa menimbulkan gangguan pada bagian-bagian tersebut".Dengan demikian dapat disimpulkan kelentukan ialah kemampuan atlet melakukan gerak dalam ruang sendi.Kelentukan merupakan faktor yang penting pada semua aspek gerakan pada manusia, terutama gerakan pada olahraga.Yaitu cabang-cabang olahraga yang banyak menuntut gerak sendi seperti senam, loncat indah dan nomor-nomor atletik.Disamping itu kelentukan penting bagi semua orang dan segala umur, terutama sekali untuk orang tua karena sendi, ligamen dan tendonnya menjadi semakin kaku sehingga kelentukan semakin berkurang.

\section{METODE PENELITIAN}

Metode penelitian yang digunakan adalah metode deskriptif dengan pendekatan studi korelasional.Metode deskriptif adalah suatu penelitian yang bertujuan untuk mendapatkan informasi mengenai fenomena-fenomena atau situasi yang aktual atau situasiyang ada pada saat penelitian berlangsung.Sugiyanto (1993: 52) menyatakan bahwa, "jenis penelitian yang dapat digolongkan atau diklasifikasi sebagai penelitian deskriptif adalah survey, studi kasus, studi perkembangan, studi follow-up, analisis dokumenter.studi arah dan studi korelasional". 
Studi korelasional digunakan untuk menguji hipotesis yang telah dirumuskan sebelumnya.Dalam hipotesis dinyatakan bahwa ada hubungan antara satu variabel dengan variabel yang lain, maka prosedur korelasional dapat digunakan untuk menguji hipotesis tersebut.

\section{HASIL PENELITIAN}

Hasil analisis korelasi dan analisis regresi antara data tes Kekuatan Otot Lengan $\left(X_{1}\right)$, Panjang Lengan $\left(X_{2}\right)$, Kelentukan Otot punggung $\left(X_{3}\right)$ dengan Kemampuan Lempar Turbo ( $\mathrm{Y}$ ) penelitian ini adalah:

\section{Analisis Korelasi Tiap Prediktor}

Hasil analisis korelasi masing-masing prediktor dengan kriterium penelitian ini adalah sebagai berikut:

a. Berdasarkan analisis korelasi antara Kekuatan Otot Lengan $\left(\mathbf{X}_{1}\right)$ dengan Kemampuan Lempar Turbo (Y), diperoleh koefisien korelasi sebesar 0,417 . Dengan $N=30$, nilai $r_{\text {tabel } 5 \%}=0,361$. Ternyata $r_{\text {hitung }}=0,417>r_{\text {tabel }}$ $5 \%=0,361$. Hal ini menunjukkan bahwa terdapat hubungan yang signifikan antara Kekuatan Otot Lengan $\left(X_{1}\right)$ dengan Kemampuan Lempar Turbo (Y).

b. Berdasarkan analisis korelasi antara Panjang Lengan $\left(\mathrm{X}_{2}\right)$ dengan Kemampuan Lempar Turbo $(\mathrm{Y})$, diperoleh koefisien korelasi sebesar 0,456 . Dengan $N=30$, nilai $r_{\text {tabel } 5 \%}=0,361$. Ternyata $r_{\text {hitung }}=0,456>r_{\text {tabel }}$ $5 \%=0,361$. Hal ini menunjukkan bahwa terdapat hubungan yang signifikan antara Panjang Lengan $\left(X_{2}\right)$ dengan Kemampuan Lempar Turbo (Y).

c. Berdasarkan analisis korelasi antara Kelentukan Otot punggung $\left(X_{3}\right)$ dengan Kemampuan Lempar Turbo (Y), diperoleh koefisien korelasi sebesar 0,385 . Dengan $N=30$, nilai $r_{\text {tabel }} 5 \%=0,361$. Ternyata $r_{\text {hitung }}=$ $0,385>r_{\text {tabel } 5 \%}=0,361$. Hal ini menunjukkan bahwa terdapat hubungan 
yang signifikan antara Kelentukan Otot punggung $\left(X_{3}\right)$ dengan

Kemampuan Lempar Turbo (Y).

Ringkasan hasil analisis korelasi masing-masing prediktor dengan kriterium penelitian ini adalah sebagai berikut:

Tabel 7. Rangkuman Hasil Analisis Korelasi Tiap Prediktor dengan Kriterium

\begin{tabular}{|l|l|l|l|}
\hline Variabel & $r_{\text {hitung }}$ & $r_{\text {tabel }}$ & Simpulan \\
\hline $\mathrm{X}_{1} \mathrm{Y}$ & 0.417 & 0,361 & Korelasi signifikan \\
\hline $\mathrm{X}_{2} \mathrm{Y}$ & 0.456 & 0,361 & Korelasi signifikan \\
\hline $\mathrm{X}_{3} \mathrm{Y}$ & 0.386 & 0,361 & Korelasi signifikan \\
\hline
\end{tabular}

\section{Analisis Regresi}

Analisis regresi yang dilaksanakan pada penelitian ini menggunakan analisis regresi ganda tiga prediktor. Hasil analisis regresi antara data tes Kelentukan Otot punggung $\left(X_{1}\right)$, Kekuatan Otot Lengan $\left(X_{2}\right)$, Panjang Lengan $\left(\mathrm{X}_{3}\right)$ Kelentukan Otot punggung dengan Kemampuan Lempar Turbo (Y) penelitian ini adalah sebagai berikut:

a. Persamaan garis regresinya adalah:

$$
\hat{y}=0.137 X_{1}+0.192 X_{2}+0.187 X_{3}+-3.245
$$

b. Koefisien korelasi dan determinasi antara prediktor dan kriterium:

$$
\begin{aligned}
& R_{y(1,2,3)}=0.676 \\
& R_{y(1,2,3)}^{2}=0.457
\end{aligned}
$$

c. Uji signifikansi analisis regresi.

Hasil uji signifikansi regresi penelitian ini dapat dilihat pada tabel berikut : 
Tabel 8. Ringkasan Hasil Analisis Regresi

\begin{tabular}{|l|l|l|l|l|}
\hline Sumber Variasi & db & JK & RK & Freg \\
\hline Regresi (reg) & 3 & 95.6041 & 31.8680 & 7.3101 \\
\hline Residu (res) & 26 & 113.3463 & 4.3595 & - \\
\hline Total & 29 & 208.9504 & - & - \\
\hline
\end{tabular}

Dari hasil analisis regresi tersebut dapat disimpulkan, dengan $\mathrm{db}=\mathrm{m}$ lawan $\mathrm{N}-\mathrm{m}-1$ = 3 lawan 26 , harga $\mathrm{F}_{\text {tabel }}$ \%\% adalah 2,89. Sedangkan nilai $\mathrm{F}$ yang diperoleh adalah 7.3101, ternyata lebih besar dari angka batas penolakan hipotesa nol. Dengan demikian hipotesa nol ditolak, yang berarti bahwa terdapat hubungan yang signifikan antara Kekuatan Otot Lengan $\left(\mathrm{X}_{1}\right)$, Panjang Lengan $\left(\mathrm{X}_{2}\right)$, Kelentukan Otot punggung $\left(\mathrm{X}_{3}\right)$ dengan Kemampuan Lempar Turbo $(\mathrm{Y})$. Adapun besarnya nilai $R^{2}$ antara Kekuatan Otot Lengan $\left(X_{1}\right)$, Panjang Lengan $\left(X_{2}\right)$, Kelentukan Otot punggung $\left(\mathrm{X}_{3}\right)$ dengan Kemampuan Lempar Turbo $(\mathrm{Y})$ adalah 0 , 457.

\section{Pengujian Hipotesis dan Pembahasan}

1. Hubungan Antara Kekuatan Otot Lengan dengan Kemampuan Lempar Turbo

Dari hasil analisis korelasi pada data Kekuatan Otot Lengan dengan Kemampuan Lempar Turbo, diperoleh nilai $r$ sebesar 0,417 , dimana nilai tersebut lebih besar dari nilai $r_{\text {tabel }}$ pada taraf signifikansi $5 \%$ yaitu 0,361. Karena nilai $r_{\text {hitung }}>r_{\text {tabel, }}$ maka nilai korelasi signifikan. Hal ini berarti bahwa perubahan variansi Kemampuan Lempar Turbo dipengaruhi oleh komponen variansi Kekuatan Otot Lengan.

\section{Hubungan Antara Panjang Lengan dengan Kemampuan Lempar Turbo}

Berdasarkan hasil analisis yang telah dilaksanakan terhadap data Panjang Lengan terhadap Kemampuan Lempar Turbo, diperoleh nilai $r$ 
sebesar 0,456, dimana nilai tersebut lebih besar dari nilai $r_{\text {tabel }}$ pada taraf signifikansi $5 \%$ yaitu 0,361. Karena nilai $r_{\text {hitung }}>r_{\text {tabel, }}$ maka nilai korelasi signifikan. Hal ini berarti bahwa variansi unsur Panjang Lengan berpengaruh terhadap peningkatan variansi Kemampuan Lempar Turbo.

3. Hubungan Antara Kelentukan Otot punggung dengan Kemampuan Lempar Turbo

Berdasarkan hasil analisis yang telah dilaksanakan terhadap data Kelentukan Otot punggungterhadap Kemampuan Lempar Turbo, diperoleh nilai $r$ sebesar 0,386 , dimana nilai tersebut lebih besar dari nilai $r_{\text {tabel }}$ pada taraf signifikansi $5 \%$ yaitu 0,361 . Karena nilai $r_{\text {hitung }}>r_{\text {tabel, }}$ maka nilai korelasi signifikan. Dengan demikian dapat disimpulkan bahwa Kelentukan Otot punggung memiliki hubungan yang signifikan terhadap Kemampuan Lempar Turbo.

4. Hubungan Kekuatan Otot Lengan, Panjang Lengan dan Kelentukan Otot punggung dengan Kemampuan Lempar Turbo

Pada Hipotesis dinyatakan bahwa hubungan antara Kekuatan Otot Lengan, Panjang Lengan dan Kelentukan Otot punggung dengan Kemampuan Lempar Turbo di ketahui $R_{y(123)}^{2}=0,457$ sedangkan $r_{\text {tabel }}$ pada taraf signifikasi 0,05 dan $n=30$ di dapat $r_{\text {tabel }}=0,361$, dengan hasil tersebut $r_{\text {hitung }}>r_{\text {tabel5 \% }}$ dan $f_{\text {hitung }}=7.7691$, sedangkan $f_{\text {tabel5\% }}$ dengan $d b 3: 26=2,89$, ini berarti $\mathrm{F}_{0}>\mathrm{F}_{\text {tabel5\% }}$ Maka hipotesis di terima.

\section{SIMPULAN, IMPLIKASI DAN SARAN}

\section{A. Simpulan}

Berdasarkan hasil penelitian dan hasil analisis regresi dan korelasi product moment yang telah dilaksanakan dapat diperoleh simpulan sebagai berikut:

1. Ada hubungan yang signifikan antara Kekuatan Otot Lengan dengan Kemampuan Lempar Turbo, $r_{\text {hitung }}=0,417>r_{\text {tabel } 5 \%}=0,361$. 
2. Ada hubungan yang signifikan antara Panjang Lengan dengan Kemampuan Lempar Turbo, $r_{\text {hitung }}=0,456>r_{\text {tabel } 5 \%}=0,361$.

3. Ada hubungan yang signifikan antara Kelentukan Otot punggung dengan Kemampuan Lempar Turbo, $r_{\text {hitung }}=0,386>r_{\text {tabel } 5 \%}=0,361$.

4. Ada hubungan yang signifikan antara Kekuatan Otot Lengan, Panjang Lengan dan Kelentukan Otot punggung dengan Kemampuan Lempar Turbo, $R_{y(123)}^{2}$ sebesar $0,457>r_{\text {tabel5 }} \%$ pada taraf signifikansi $5 \%$ sebesar 0.361 dan $F_{0}$ sebesar $7.3101>f_{\text {tabel }}$ pada taraf signifikansi $5 \%$ sebesar 2,89 .

\section{B. Saran}

Sehubungan dengan simpulan yang telah diambil, maka kepada guru olahraga, khususnya di Sekolahan, disarankan agar:

1. Dalam upaya untuk meningkatkan Kemampuan Lempar Turbo hendaknya memberikan latihan Kekuatan Otot Lengan, Panjang Lengan dan Kelentukan Otot punggung.

2. Latihan fisik yang diberikan harus proporsional. Besarnya porsi latihan untuk tiap unsur Kekuatan Otot Lengan, Panjang Lengan dan Kelentukan Otot punggung disesuaikan dengan besarnya nilai hubungan tiap variabel terhadap Kemampuan Lempar Turbo.

\section{DAFTAR PUSTAKA}

A. Hamidsyah Noer.1995. limit Kepelatihan Lanjut. Surakarta: UNS Press.

Agus Kristianto. 2005. Perkembangan Motonk Surakarta: Hibah Pengajaran SP4 Batch II Tahun I UNS.

Aip Syarifuddin.1992. Atletik.Jakarta: Departemen Pendidikan dan Kebudayaan. Andi Suhendro.2002. Dasar-dasar Kepelatihan.Jakarta: Universitas Terbuka.

Depdikbud. 1997. Pedoman Atletik untuk Kluh Olahraga di SD. Jakarta: Kantor Menteri Negara Pemuda dan Olahraga. 
Gerry A. Carr. 1997. Atletik untuk Sekolah. Jakarta: PT. Raja Graflndo Persada.

Isniaryati. 2006. Tesdan Pengukuran Olahraga Surakarta: Sebelas Maret University Press.

Jarver, J. 1982. Belajar dan Berlatih Atletik, Bandung: Penerbit Pioner.

Johnson, B.L. and Nelson, J.K. 1986. Practical Measurements for Evaluation in Physical Education. New York: Macmillan Publishing Company.

Jonath, U.,E. Haag dan R. Krempel. 1987. Atletik I Alih Bahasa Suparno. Jakarta: PT. Rosda Jaya Putra.

M. Sajoto. 1995. Peningkatan dan Pembinaan Kondisi Fisik dalam Olahraga. Semarang: Dahara Prize.

PASI.2000. Petunjuk Pelaksanaan Lomba Atletik.

Suyono.2002. IAAF Kid's Atletics. Jakarta. A Team Event for Children IAAF Kid's Atletics.

Samsir Riyadi. 1985. Petunjuk Atltetik Cetakan II. Yogyakarta: FPOK MIP Yogyakarta. 